\title{
Electrical, Mechanical, and Thermal Analysis of Natural Rubber/Polyaniline-Dbsa Composite
}

\author{
Michael Jonas da Silva, Aléx Otávio Sanches, Luiz Francisco Malmonge, José Antonio Malmonge* \\ Departamento de Física e Química, Faculdade de Engenharia, \\ Univ Estadual Paulista - UNESP, Ilha Solteira, SP, Brazil
}

Received: June 20, 2013; Revised: March 18, 2014

\begin{abstract}
A composite of natural rubber (NR) with polyaniline (PANI) was obtained by mixing an aqueous dispersion of dodecylbenzenesulfonic acid (DBSA)-doped PANI with NR latex in different concentrations. Films were obtained by the casting method and characterized by ultraviolet visible near-infrared (UV-Vis-NIR) spectroscopy, thermogravimetry/differential thermogravimetry (TG/ DTG), stress-strain testing, differential scanning calorimetry (DSC), and DC electrical conductivity measurements. The UV-vis-NIR spectrum showed that PANI remained doped in the composite, and this improved the mechanical and electrical proprieties of NR films and afforded them good thermal stability up to $\sim 200^{\circ} \mathrm{C}$. The percolation threshold did not follow the universal critical exponent, and in this case, conduction preferentially occurs by hopping and tunneling.
\end{abstract}

Keywords: natural rubber, polyaniline, electrical conductivity, percolation threshold

\section{Introduction}

Among currently available intrinsically conducting polymers (ICP), polyaniline (PANI) has emerged as one of the most promising ones for technological applications owing to its good electrical properties, environmental stability, low production cost, and ease of synthesis ${ }^{1,2}$. As a result, PANI is considered a strong candidate for applications such as sensors, electromagnetic shielding (EMI), corrosion protection, and actuators ${ }^{1-3}$. However, PANI's applications are limited by its poor infusibility, low solubility in organic solvents, and poor mechanical properties ${ }^{2}$. PANI's solubility can be improved by using organic acids such as dodecylbenzenesulfonic acid (DBSA) and p-toluenesulfonic acid (PTSA) that not only improve the compatibility of PANI with the host matrix but also acts as dopants, thus increasing the electrical conductivity of the material ${ }^{4}$. PANI's mechanical properties can be improved by mixing it with a polymeric host matrix to form composites or blends ${ }^{3-25}$. Many polymeric materials can be used as supports for PANI, such as cellulose nanofiber ${ }^{5}$, epoxy resin ${ }^{7}$, polyvinyl chloride (PVC) ${ }^{4}$, polyurethane ${ }^{8}$, poly (methyl methacrylate) $(\mathrm{PMMA})^{9}$, and rubbers ${ }^{10-25}$. Among polymeric matrixes, natural rubber (NR) has been increasingly used for forming composites owing to its unique mechanical properties. NR is extensively used in various products that require superior properties such as elasticity, flexibility, and resilience.

NR/PANI blends and composites have already been obtained using different methods such as mill mixing ${ }^{14}$, solution/dispersion mixing ${ }^{11,12,16,22}$, and electrochemical ${ }^{17}$ and chemical polymerization ${ }^{10}$ of aniline in the presence of a host matrix. However, few studies have focused on NR/ PANI composites obtained by a mixture of PANI dissolved in an organic solvent with NR latex ${ }^{10-12}$.

*e-mail: mal@dfq.feis.unesp.br
In this study, NR/PANI-DBSA composites were obtained by mixing NR latex and an aqueous dispersion of DBSAdoped PANI in different concentrations. These composites were characterized by ultraviolet visible near-infrared (UV-Vis-NIR) spectroscopy, thermogravimetric/differential thermogravimetric (TG/DTG) analysis, differential scanning calorimetry (DSC), stress-strain measurements, and DC electrical conductivity measurements. It was found that PANI-DBSA improved the mechanical proprieties of NR and that the composite showed low electrical percolation threshold.

\section{Material and Methods}

\subsection{Material}

Analytical grade aniline was purchased from SigmaAldrich, distilled under vacuum, and stored in a refrigerator before being polymerized. Ammonium peroxydisulfate (APS) and DBSA (70 wt\% in 2-propanol) were purchased from Sigma-Aldrich and used as received. NR latex was collected from Hevea brasiliensis trees (Clone RRIM 600) planted in the Experimental Farm of the University of São Paulo State (UNESP), campus of Ilha Solteira, Brazil, and stabilized in a commercial solution of ammonium hydroxide to avoid coagulation. The dry rubber content was determined by standard methods ${ }^{13}$.

\subsection{Synthesis of PANI-DBSA}

An aqueous dispersion of PANI-DBSA complex was prepared by the oxidative polymerization of aniline in the presence of DBSA in aqueous media. In a typical procedure, $1.0 \mathrm{~mL}$ of aniline and $7.6 \mathrm{~mL}$ of DBSA were mixed in $500 \mathrm{~mL}$ of deionized water under constant stirring. After 
$1 \mathrm{~h}, 10 \mathrm{~mL}$ of an aqueous solution containing $0.61 \mathrm{~g}$ of APS was added to the mixture. The medium was kept at $5^{\circ} \mathrm{C}$ under magnetic stirring and after $12 \mathrm{~h}$ of reaction, the PANI-DBSA complex was separated from the medium by centrifugation. PANI-DBSA was re-dispersed in water and centrifuged again. This procedure was repeated three times, and the final content was either re-dispersed in water in the desirable concentration (e.g., for characterization) or kept at high concentration.

\subsection{Preparation of NR/PANI-DBSA composite}

The NR/PANI-DBSA composite was obtained by the mixture of PANI-DBSA aqueous solution $(5.2 \mathrm{w} / \mathrm{v})$ in NR latex $(\mathrm{pH}=7.0,41.0 \mathrm{w} / \mathrm{v}$ of $\mathrm{NR})$ at concentrations of $3-10 \mathrm{wt} \%$. The mixture was kept under constant stirring for $2 \mathrm{~h}$ at ambient temperature, following which it was cast on a glass substrate and dried in a conventional oven at $60^{\circ} \mathrm{C}$ for $12 \mathrm{~h}$ to obtain $\sim 200-\mu \mathrm{m}$-thick films.

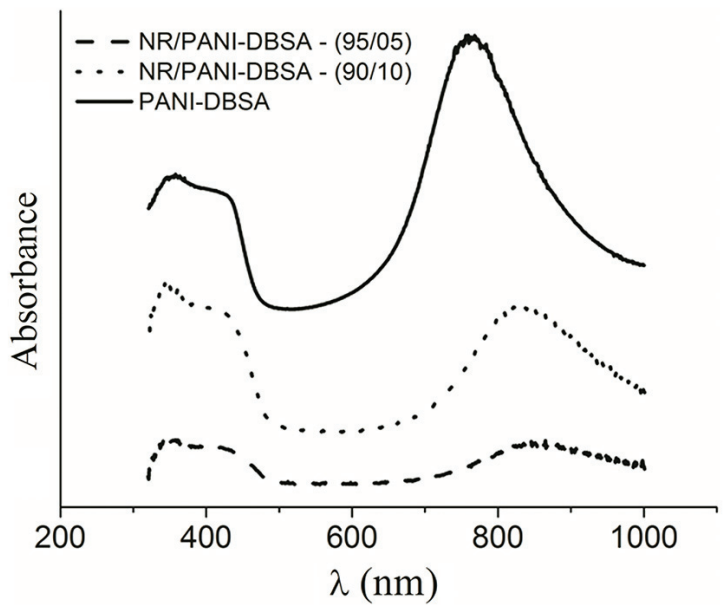

Figure 1. UV-Vis-NIR spectra of PANI-DBSA and the NR/PANIDBSA composite.

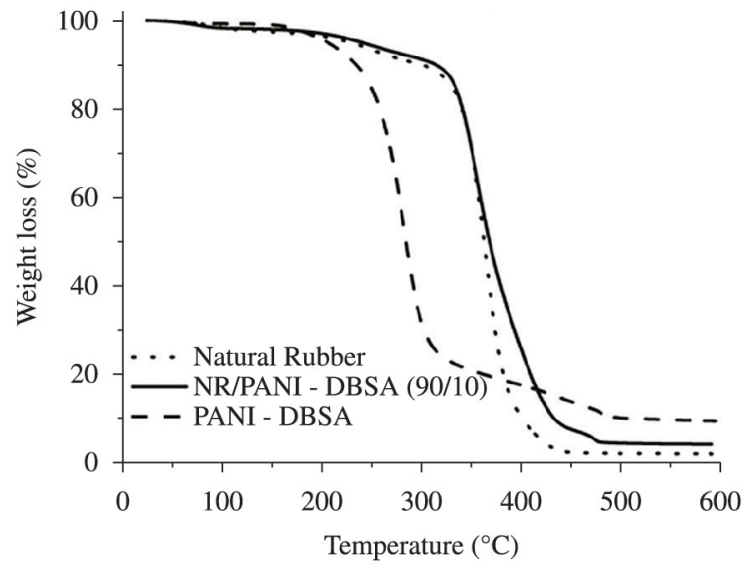

(a)

\subsection{Methods}

UV-Vis-NIR absorption spectra of NR/PANI-DBSA films were obtained using a Cary 50 spectrophotometer (Varian). Spectra were recorded from 300-1000 nm. Thermogravimetric analysis was carried out in the temperature range of $25-600^{\circ} \mathrm{C}$ at a heating rate of $10^{\circ} \mathrm{C} / \mathrm{min}$ in nitrogen atmosphere with a flow rate of $60 \mathrm{~mL} / \mathrm{min}$ using a Q500 (TA Instruments). Approximately $10 \mathrm{mg}$ were used for each sample. The glass transition temperature $\left(T_{g}\right)$ of the samples $(10.0 \mathrm{mg}$ ) was measured using a MDSC 292 (TA Instruments) with a scan rate of $10^{\circ} \mathrm{C} / \mathrm{min}$ within the temperature range of -100 to $150^{\circ} \mathrm{C}$ under nitrogen atmosphere.

Mechanical tests were conducted in accordance with ASTM D882 using an Instron tensometer at a crosshead speed of $500 \mathrm{~mm} / \mathrm{min}$ and a $100-\mathrm{N}$ load cell. Electrical conductivity measurements of the samples were carried out using a two-probe method. Gold electrodes were evaporated onto both faces of the film for electrical contact. A power source that provides a constant voltage and measures the current (Model 247, Keithley Instruments) was used to measure the current through the sample. The electrical conductivity $\sigma(\mathrm{S} / \mathrm{cm})$ was calculated according to Equation 1:

$\sigma=\frac{I \cdot A_{e}}{V \cdot d}$

where $\mathrm{d}(\mathrm{cm})$ is the thickness of the film; I (A), the current driven through the sample; $\mathrm{A}_{\mathrm{e}}\left(\mathrm{cm}^{2}\right)$, the electrode area; and $\mathrm{V}(\mathrm{V})$, the applied voltage.

\section{Results and Discussion}

UV-Vis-NIR absorption spectra of DBSA-doped PANI and the NR/PANI-DBSA composite are shown in Figure 1. Three bands are observed in the PANI-DBSA spectrum, indicating that the polymer is in its emeraldine salt form. The band at $340 \mathrm{~nm}$ is assigned to the $\pi-\pi^{*}$ transition of benzene rings and those at $\sim 800 \mathrm{~nm}$ and $\sim 420 \mathrm{~nm}$, to polaron bands related to the doping process and conductivity of $\mathrm{PANI}^{5,10,19}$.

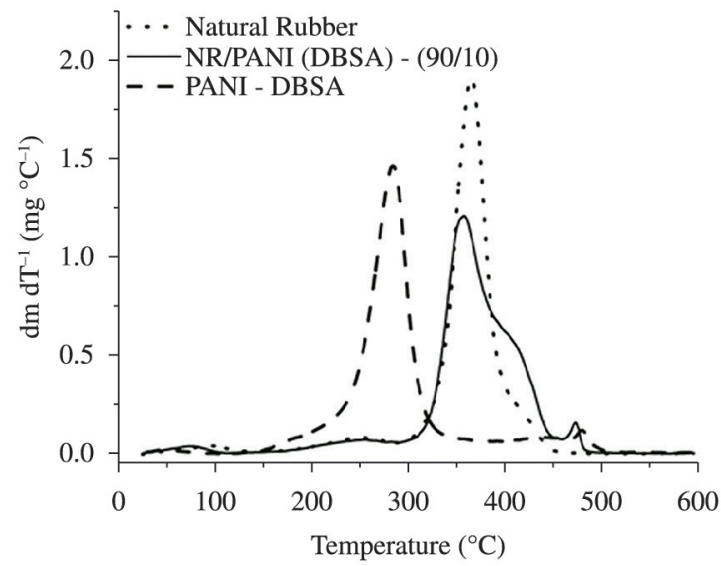

(b)

Figure 2. (a) TG and (b) DTG curves of neat NR, PANI-DBSA, and NR/PANI-DBSA composite. 
The same bands are observed in the UV-VIS-NIR spectra of NR/PANI-DBSA composites, indicating that the high $\mathrm{pH}$ of natural latex did not lead to the dedoping of PANI.

Figure 2 shows typical TG/DTG curves obtained for the neat NR, PANI-DBSA, and NR/PANI-DBSA composite with $10 \mathrm{wt} \%$ of PANI-DBSA. The TG curve of DBSA-PANI shows three main weight loss stages. The first weight loss occurred before $100^{\circ} \mathrm{C}$ owing to the loss of water and other volatiles; the second, in a temperature range of $200-350^{\circ} \mathrm{C}$ owing to the evaporation and degradation of DBSA and the oxidation of the PANI structure ${ }^{20,21}$; and the third, in

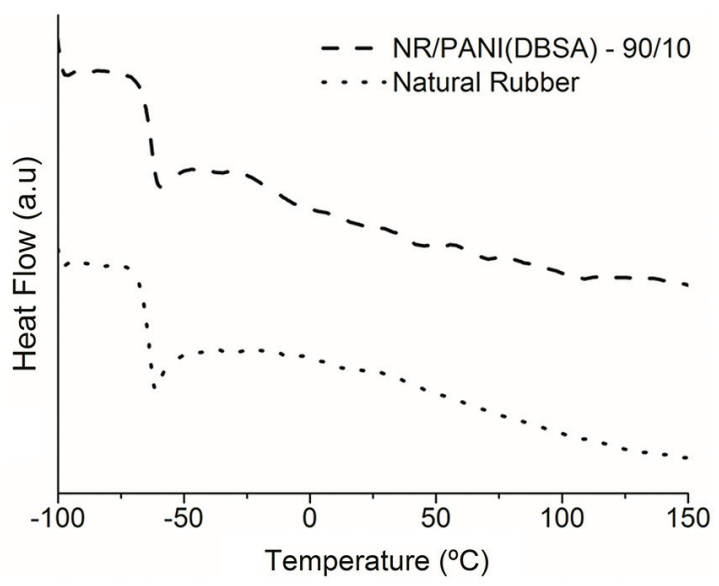

Figure 3. DSC curves of the neat NR sample and NR/PANI-DBSA composite.

Table 1. Young's modulus $(E)$, tensile strength $\left(\sigma_{r}\right)$, and elongation $\left(\varepsilon_{r}\right)$ at the break of the neat NR and NR/PANI-DBSA composite films with proportions of 95/05 and 90/10.

\begin{tabular}{lccc}
\hline \multicolumn{1}{c}{ Samples } & $E(\mathbf{M P a})$ & $\sigma_{\mathbf{r}}(\mathbf{M P a})$ & $\varepsilon_{\mathrm{r}}(\boldsymbol{\%})$ \\
\hline NR & $0.68 \pm 0.05$ & $1.36 \pm 0.04$ & $766 \pm 9$ \\
NR/PANI-DBSA-95/05 & $1.00 \pm 0.30$ & $2.10 \pm 0.20$ & $699 \pm 2$ \\
NR/PANI-DBSA-90/10 & $1.50 \pm 0.20$ & $2.20 \pm 0.10$ & $695 \pm 7$ \\
\hline
\end{tabular}

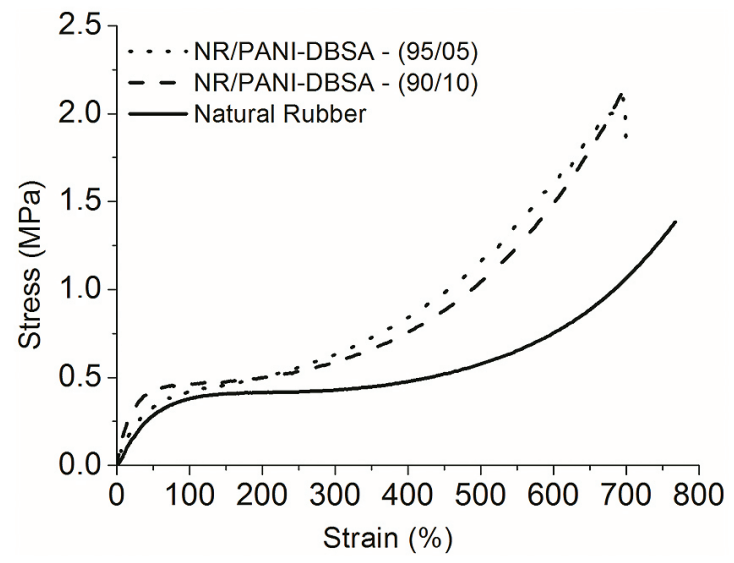

Figure 4. Stress-strain curves of the samples of the NR/PANI-DBSA composite films with proportions of $95 / 05$ and $90 / 10$ and neat NR. a relatively wide temperature range of $400-500^{\circ} \mathrm{C}$ owing to the degradation of the bound PANI-DBSA and the decomposition of PANI ${ }^{20,21}$.

The TG/DTG curves of the neat NR and composite basically show the same decomposition mechanism. The NR TG profile shows remarkable weight loss in the temperature range of $300-450^{\circ} \mathrm{C}$ corresponding to the structural decomposition of rubber in nitrogen atmosphere ${ }^{26}$. The NR/PANI-DBSA composite also showed a peak at $\sim 370^{\circ} \mathrm{C}$ (major peak) that was mainly attributed to rubber decomposition and two discrete weight loss steps in the temperature ranges of $60-100^{\circ} \mathrm{C}$ and $400-500^{\circ} \mathrm{C}$, corresponding to the loss of water and the degradation of PANI and DBSA bounded in the composite, respectively.

The effect of the addition of PANI-DBSA on the $T_{g}$ of NR was investigated by DSC, and the results did not show a significant change in the $T_{g}$ of NR with addition of up to $10 \mathrm{wt} \%$ of PANI-DBSA, as shown in Figure 3. In both samples, the $T_{g}$ was around $-63^{\circ} \mathrm{C}$.

Stress-strain tests were performed under uniaxial extension; Table 1 shows the analytical results of the mechanical properties and Figure 4, the tensile curves. The addition of PANI-DBSA improved the mechanical properties of the composites. Both Young's modulus (determined from the initial slope of the tensile curves) and tensile strength significantly increased with the addition of PANI-DBSA to rubber.

This effect is attributed to the rigidity of PANI. Increasing the PANI-DBSA content in the composite to $10 \mathrm{wt} \%$ led to no significant change in the tensile profile compared to a proportion of $5 \mathrm{wt} \%$. This behavior can be related to the amount of water uptake in the composite owing to the hygroscopic characteristics of DBSA-doped PANI ${ }^{27}$.

Figure 5 shows the electrical conductivity of the composite films as a function of the PANI-DBSA content. The conductivity increased with an increase in the PANIDBSA content in the NR matrix, reaching a value of $10^{-6} \mathrm{~S} / \mathrm{cm}$ for $10 \mathrm{wt} \%$ of PANI-DBSA. The percolation threshold was found to be $\sim 3.1 \mathrm{wt} \%$.

By percolation theory, when a conducting continuous network is formed in the composite through connections

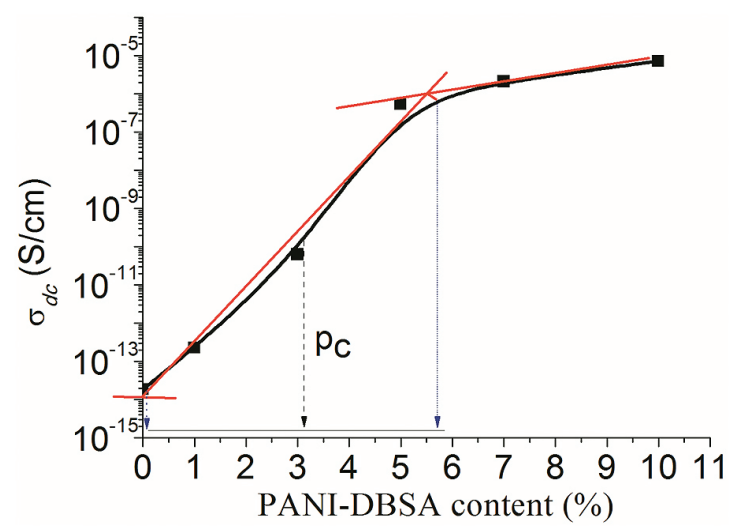

Figure 5. Electrical conductivity of NR/PANI-DBSA composites as a function of PANI-DBSA content. 


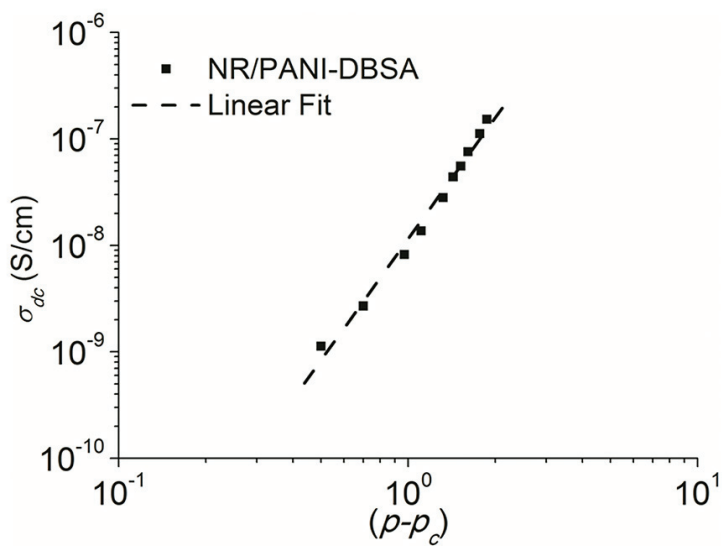

Figure 6. Double-logarithmic plot according to Equation 1.

between adjacent conducting particles, the electrical conductivity behavior can be calculated using a typical power-law ${ }^{28,29}$ :

$\sigma=k\left(p_{c}-p\right)^{t}$

where $p_{c}$ is the critical concentration or percolation threshold; $p$, the concentration of the conductive phase; $k$, a constant; and $t$, the conductivity critical exponent. The data from Figure 5 were fitted to a plot of $\log (\sigma)$ versus $\log$ $\left(p-p_{c}\right)$ according to Equation 2, as illustrated in Figure 6, to estimate the values of the critical exponent $(t)$ and constant $(k)$. The values $t$ and $k$ were estimated by fitting the data shown in Figure 6, in which the values were $t=3.3$ and $k=3.7 \times 10^{-9}$.

In polymeric composites filled with a low proportion of conducting particles, the mean distance between particles or clusters is sufficiently large and the conductivity is restricted by the presence of the polymeric matrix. However, by

\section{References}

1. Chen CH. Thermal studies of polyaniline doped with dodecyl benzene sulfonic acid directly prepared via aqueous dispersions. Journal of Polymer Research. 2002; 9(3):195-200. http://dx.doi.org/10.1023/A:1021395726060

2. Bhadra S, Khastgir D, Singha NK and Lee JH. Progress in preparation, processing and applications of polyaniline. Progress in Polymer Science. 2009; 34(8):783-810. http:// dx.doi.org/10.1016/j.progpolymsci.2009.04.003

3. Mattoso LHC, Medeiros ES, Baker DA, Avloni J, Wood DF and Orts WJ. Electrically conductive nanocomposites made from cellulose nanofibrils and polyaniline. Journal of Nanoscience and Nanotechnology. 2008; 8(5):2917-2922.

4. Afzal AB, Akhtar MJ and Ahmad M. Morphological studies of DBSA-doped polyaniline/PVC blends. Journal of Electron Microscopy. 2010; 59(5):339-344. PMid:20601353. http:// dx.doi.org/10.1093/jmicro/dfq050

5. Silva MJ, Sanches AO, Malmonge LF, Medeiros ES, Rosa MF, McMahan CM et al. Conductive nanocomposites based on cellulose nanofibrils coated with polyaniline-DBSA via In Situ polymerization. Macromolecular Symposia. 2012; 319(1):196202. http://dx.doi.org/10.1002/masy.201100156 increasing the conducting phase content at the percolation threshold, a physical path is formed. The $t$ value obtained is larger than that obtained by the universal percolation theory. The behavior of the nonuniversal critical exponent of conductivity in polymer composites has been reported in literature ${ }^{30,31}$; it is attributed to the formation of an electrical percolation network in which the particles are not in direct physical contact ${ }^{32}$. In this case, the conduction process in the composite preferentially occurs via hopping and tunneling of charge carriers between neighboring particles or particles clusters ${ }^{32}$.

Above the percolation threshold, the electrical conductivity of the composite increased by seven orders of magnitude compared to that of neat NR $\left(10^{-14} \mathrm{~S} / \mathrm{cm}\right)$.

\section{Conclusion}

An NR/PANI-DBSA composite was obtained by incorporating an aqueous dispersion of DBSA-doped PANI into NR latex, and films of the composite were obtained by casting methods. The mechanical and electrical proprieties of the NR films were improved by the incorporation of PANI-DBSA with good thermal stability up to $\sim 200^{\circ} \mathrm{C}$. The percolation threshold $\left(p_{c}\right)$ and critical exponent values were $p_{c}=3.1$ and $t=3.3$, respectively. The behavior of the nonuniversal critical exponent was attributed to electrical percolation. For a composite with $10 \%$ of PANI-DBSA content, an electrical conductivity of $\sim 10^{-6} \mathrm{~S} / \mathrm{cm}$ was attained, which is seven orders of magnitude higher than that of neat NR.

\section{Acknowledgments}

The authors acknowledge the CNPQ (Conselho Nacional de Desenvolvimento Científico e Tecnológico) and FAPESP (Fundação de Amparo à Pesquisa do Estado de São Paulo) for financial support.

6. Zilberman M, Titelman GI, Siegmann A, Haba Y, Narkis M and Alperstein A. Conductive blends of thermally dodecylbenzene sulfonic acid-doped polyaniline with thermoplastic polymers. Journal of Applied Polymer Science. 1997; 66(2):243253. http://dx.doi.org/10.1002/(SICI) 1097 4628(19971010)66:2<243::AID-APP5>3.0.CO;2-W

7. Soares BG, Celestino ML, Magioli M, Moreira VX and Khastgir D. Synthesis of conductive adhesives based on epoxy resin and polyaniline. DBSA using the in situ polymerization and physical mixing procedures. Synthetic Metals. 2010; 160:1981-1986. http://dx.doi.org/10.1016/j. synthmet.2010.07.021

8. Diniz FB, Andrade GF, Martins CR and Azevedo WM. A comparative study of epoxy and polyurethane based coatings containing polyaniline-DBSA pigments for corrosion protection on mild steel. Progress in Organic Coatings. 2013; 76:912-916. http://dx.doi.org/10.1016/j.porgcoat.2013.02.010

9. Fattouma A, Othman ZB and Arous M. Dc and Ac conductivity of polyaniline/poly(methyl methacrylathe) blends below the percolation threshold. Materials Chemistry and Physics. 2012; 135(1):117-122. http://dx.doi.org/10.1016/j. matchemphys.2012.04.033 
10. Galiani PD, Malmonge JA, Santos DP and Malmonge LF. Compósitos de borracha natural com polianilina. Polímeros. 2007; 17(2):93-97. http://dx.doi.org/10.1590/ S0104-14282007000200007

11. Camillo EC, Constantino CJL, Teruya MY, Alves N, Mattoso LHC and Job AE. Dependence of the electrical conductivity and elastomeric properties on sample preparation of blends of polyaniline and natural rubber. Journal of Applied Polymer Science. 2005; 97(4):1498-1503. http://dx.doi.org/10.1002/ app. 21899

12. Sukitpaneenit P, Thanpitcha T, Sirivat A, Weder C and Rujiravanit R. Electrical conductivity and mechanical properties of polyaniline/natural rubber composite fibers. Journal of Applied Polymer Science. 2007; 106(6):4038-4046. http://dx.doi.org/10.1002/app.27101

13. Malmonge JA, Camilo EC, Moreno RMB, Mattoso LHC and McMahan CM. Comparative study on the technological properties of latex and natural rubber from hancornia speciosa gomes and Hevea brasiliensis. Journal of Applied Polymer Science. 2009; 111(6):2986-2991. http://dx.doi.org/10.1002/ app. 29316

14. Al-Ghamdi AA, Al-Hartomy OA, Al-Solamy F, Al-Hazmi F, Al-Ghamdi AA, El-Mossalamy EH et al. On the prospects of conducting polyaniline/natural rubber composites for electromagnetic shielding effectiveness applications. Journal of Thermoplastic Composite Materials. 2012; 1-18.

15. John H, Joseph R and Mathew KT. Dielectric behavior of natural rubber composites in microwave fields. Journal of Applied Polymer Science. 2007; 103(4):2682-2686. http:// dx.doi.org/10.1002/app. 25420

16. Kalasad MN, Gadyal MA, Hiremath RK, Ikram IM, Mulimani BG, Khazi IM et al. Synthesis and characterization of polyaniline rubber composites. Composites Science and Technology. 2008; 68(7-8):1787-1793. http://dx.doi. org/10.1016/j.compscitech.2008.02.001

17. Anisha MM, Faseena NM and Predeep P. Electrochemical synthesis of conducting natural rubber nanocomposite films. Plastics, Rubber and Composites. 2013; 42(6):264-267. http:// dx.doi.org/10.1179/1743289812Y.0000000050

18. Yong KC and Saad CSM. Novel peroxide-vulcanized NBRPAni.DBSA blends, part 1: preparation and characterization. Journal of Applied Polymer Science. 2009, 112(6):3199-3208. http://dx.doi.org/10.1002/app.29619

19. Han GM, Cho SK, Oh SG and Im SS. Preparation and characterization of polyaniline nanoparticles synthetized from DBSA micellar solution. Synthetic Metal. 2002; 126(1):53-60. http://dx.doi.org/10.1016/S0379-6779(01)00494-5

20. Han D, Chu Y, Yang L, Liu Y and Lv Z. Reversed micelle polymerization: a new route for the synthesis of DBSApolyaniline nanoparticles. Colloids and Surfaces A: Physicochemical and Engineering Aspects. 2005; 259(13):179-187. http://dx.doi.org/10.1016/j.colsurfa.2005.02.017
21. Chen T, Dong C, Li X and Gao J. Thermal degradation mechanism of dodecylbenzene sulfonic acid- hydrochloric acid co-doped polyaniline. Polymer Degradation and Stability. 2009; 94(10):1788-1794. http://dx.doi.org/10.1016/j. polymdegradstab.2009.06.011

22. Faez R and Paoli MA. A conductive rubber based on EPDM and polyaniline I. Doping effect. European Polymer Journal. 2001; 37(6):1139-1143. http://dx.doi.org/10.1016/ S0014-3057(00)00235-4

23. Soares BG, Amorim GS, Souza FG, Oliveira MG and Silva JE. The in situ polymerization of aniline in nitrile rubber. Synthetic Metals. 2006; 156(2-4):91-98. http://dx.doi.org/10.1016/j. synthmet.2005.09.045

24. Soares BG, Amorim GS, Souza FG, Oliveira MG and Silva JE. Conducting elastomer blends based on nitrile rubber and Pani.DBSA. Macromolecular Symposia. 2006; 233(1):95-101. http://dx.doi.org/10.1002/masy.200690033

25. Job AE, Constantino CJL, Mendes TSG, Teruya MY, Alves N and Mattoso LHC. Effect of natural rubber latex on the conducting state of polyaniline blends determined by Raman spectroscopy. Journal of Raman Spectroscopy. 2003; 34(10):831-836. http:// dx.doi.org/10.1002/jrs.1060

26. Oliveira LCS, Arruda EJ, Costa RB, Gonçalves PS and Delben A. Evaluation of latex from five Hevea clones grown in São Paulo State, Brazil. Thermochimica Acta. 2003; 398(1-2):259263. http://dx.doi.org/10.1016/S0040-6031(02)00225-3

27. Ostwal MM, Sahimi M and Tsotsis TT. Water harvesting using a conducting polymer: a study by molecular dynamics simulation. Physical Review E. 2009; 79(6):1-16. http://dx.doi. org/10.1103/PhysRevE.79.061801

28. Silva MJ, Kanda DHF and Nagashima HN. Mechanism of charge transport in castor oil-based polyurethane/carbon black composite (PU/CB). Journal of Non-Crystalline Solids. 2012; 358(2):270-275. http://dx.doi.org/10.1016/j. jnoncrysol.2011.09.032

29. Kirkpatrick S. Percolation and conduction. Reviews of Modern Physics. 1973; 45(4):574-588. http://dx.doi.org/10.1103/ RevModPhys. 45.574

30. Heaney MB. Measurement and interpretation of nonuniversal critical exponents in disordered conductor-insulator composites. Physical Review B. 1995; 52(17):12477-12480. http://dx.doi. org/10.1103/PhysRevB.52.12477

31. Ezquerra TA, Connor MT, Roy S, Kulescza M, FernandesNascimento J and Baltá-Calleja FJ. Alternating-current electrical properties of graphite, carbon Black and carbonfiber polymeric composites. Composites Science and Technology. 2001; 61(9):903-909. http://dx.doi.org/10.1016/ S0266-3538(00)00176-7

32. Nakamura S, Saito K and Sawa G. Electrical Field dependence of conductivity and critical exponent of it for carbon black-resin composites. Seventh International conference on Dielectric Materials Measurements \& Applications. 1996; 430(1):96-99. 